\title{
Recommendations For Prevention Of Medical Errors Through An Empirical Investigation Of The Error Reporting Systems Within Acute Care Hospitals In Pennsylvania
}

\author{
Monica L. Law, Bloomsburg University, USA
}

\begin{abstract}
The researcher investigated the procedures taken by healthcare administrators within twenty-two Pennsylvania acute care hospitals with respect to the prevention of medical errors. Structured interview questions provided relevant data in relation to how healthcare administrators could structure the workplace environment in hopes to prevent the number of medical errors that occur in acute care hospitals in Pennsylvania. Recommendations for prevention include conducting needs assessments the areas of cultural assessment, error reporting system assessment, workplace environment assessment, corrective action procedures assessment, and policies and procedures assessment. Recommendations and implications for conducting the needs assessments are provided in this paper in an effort to bring attention to actions that may be taken by hospital administrators in hopes of reducing the number of medical errors that occur within acute care hospitals in Pennsylvania.
\end{abstract}

Keywords: Medical Errors; Corrective Action; Error Reporting Systems

\section{LITERATURE REVIEW}

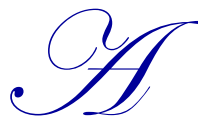

groundbreaking report distributed by The Institute for Medicine, has heightened awareness to the number of errors that occur within United States hospitals. This report states that somewhere between 44,000 to 98,000 people die from medical errors each year (Corrigan, Donaldson, \& Kohn, 2000). The Institute of Medicine has defined an error as "the failure of a planned action to be completed as intended or the use of wrong plan to achieve an aim" (Corrigan, Donaldson, \& Kohn, 2000, p. 28). More specifically, an error can be construed as a misdiagnosis, a wrong procedure performed, a medication dosing mistake, faulty equipment, and a host of other unintended acts that result in failure.

System failures have been identified as a major contributor to the occurrence of medical errors. Subsequently, research has changed its focus from individuals to systems, specifically, improving the systems to reduce errors (Adams, Jaffe, \& Rosenbloom, 2001). In addition, Cooper (2001) states "even though effective remedies do exist, much research is needed in the area of medical errors in order to learn about the underlying causes of the errors and system failures" (p. 4).

It has been stated that healthcare professionals are among the most educated and dedicated workforce in any industry, so how can this happen? Studies suggest that the problem does not lie with healthcare workers, but with the systems in which these people work. Systems need to be made safer in order to reduce the occurrence of medical errors (Corrigan, Donaldson, \& Kohn, 2000). Nancy Dickey (2000), a former president of the American Medical Association, has said "addressing what has to change in the system(s) in order for fewer errors to occur 
should be a current concern in the healthcare industry" (p. 2). Ensuring patient safety involves the establishment of systems and processes that increase the reliability of patient care.

Preventing medical errors is of utmost concern to providers of health care. The specific failures that occur are also of importance because in order to prevent errors, one must first know how the error occurred, and where the system failed. It becomes critical to assess the systems in place in order to prevent the occurrence of medical errors.

Systems must be assessed in order to evaluate potential breakdowns. Rossett (1995) described needs assessment as an initial inquiry of information about situation. Rossett (1995) incorporated the work of Bandura (1977) into a system that recognizes four kinds of causes: First, lack of knowledge or skills. In essence, can the performer do the task? Second, a flawed environment. Does the environment support the task? Third, improper incentives. What are the consequences of doing the job badly or not doing it at all? And fourth, unmotivated employees. What is their value toward the task? What is the internal state of the individuals involved? Law (2012) stated that it may be very beneficial for acute care hospitals to explore the idea of conducting needs assessments in attempting to prevent medical errors.

The Institute for Healthcare Improvement (IHI) (2013) states that an open exchange of information requires management to have a non-punitive response philosophy that rewards reporting of safety issues and events and does not punish staff members involved in errors or adverse events related to system failures. However, in order to address possible system failures, management must know what is "broken" within the system. Conducting a needs assessment may help hospital management assess what needs to change in order for systems to be repaired.

\section{PURPOSE}

The ultimate goal of this study was to help providers of healthcare within Pennsylvania acute care hospitals find solutions to the ever-present problem of the occurrence of medical errors. Scholarly literature states that the majority of medical errors occur due to systems that breakdown and fail healthcare workers. This study sought to provide new knowledge in regard to where the error reporting system may be breaking down. The purpose of this study was twofold; 1) to develop two structured interview questionnaires, and 2) to conduct structured interviews as a means to collect data that focused on the occurrence of medical errors; specifically through assessing the error reporting systems within a sample of twenty-two Pennsylvania acute care hospitals.

\section{RESEARCH QUESTION}

Research Question - Within the sampled twenty-two Pennsylvania acute care hospital error reporting systems; are procedures in place in order to prevent reoccurrence of medical errors?

Using a qualitative methodology, perceptions of patient safety officers and registered nurses within twentytwo acute care hospitals were analyzed. Twelve patient safety officers and ten nurses were interviewed. Interviews averaged forty-three minutes in length. The research question was posed in an effort to find an answer to what exists within the error reporting systems following the correction of an error, focusing specifically on prevention of errors.

\section{RESEARCH DESIGN}

The theoretical approach taken in this study was based upon an open systems model. An open systems model differs from closed systems in that the transaction between the organization and its environment is considered to be the most significant aspect of organizational phenomenon (Narayanan \& Nath, 1993). Generally, the systems approach utilizes three steps; 1 ) objectives are set, 2) a means to meet the objectives is designed, and 3) a feedback mechanism is constructed in order to determine the progress toward the attainment of the objectives. Due to the nature of the research, the researcher chose a qualitative design.

Qualitative research designs typically focuses on small numbers in regard to participants used for data collection purposes, thus rarely makes explicit claims about the generalizability of their accounts. Internal 
generalizability, the generalizability of a conclusion within the group studied, is a key issue for qualitative studies, not external generalizability (Maxwell, 1996). Qualitative researchers typically study a small number of individuals and preserve the individuality of each analysis. Thus, researchers are able to understand how events, actions, and meanings are shaped by the unique circumstances in which these occur. Qualitative studies focus on understanding processes in which events and actions take place, rather than the specific outcomes. Qualitative research does not disregard outcomes. However, the strength of the qualitative design lies at getting at the processes that lead to particular outcomes (Maxwell, 1996).

\section{FINDINGS}

In analyzing data from this research question, it was found that $100 \%$ of the patient safety officers and the nurses felt that procedures were in place in order to prevent the reoccurrence of medical errors. $70 \%$ of the nurses stated that prevention measures focused on re-education or training. $30 \%$ of the nurses could not explain the procedures that were in place to prevent errors. The following are direct statements made by nurses, in regard to the research question:

"Administration assumes that if we make an error we don't know what we are doing so they make us take a class."

“We will all make mistakes, but management makes you feel like you don't know anything if we make a mistake. They don't take the time to find out what happens, they just send us to a training course."

"Errors happen for a variety of reasons, we know that. So, why do they (administration) make us feel like we are dumb and don't know what we are doing when an error occurs? The system is broken."

$100 \%$ of the patient safety officers stated that preventive measures are in place. However, none of the respondents elaborated. The following are direct statements made by patient safety officers in regard to the research question:

"We as administration do what we can to ensure the reporting of errors, this includes making sure our error reporting system exists."

"We try to get staff to report errors, and we reduce our error rates by having an error reporting system in place."

"We correct the errors that occur, and we strive to prevent them too."

\section{CONCLUSIONS}

Even though medical errors are stated as a leading cause of death in the United States, the research participants in this study seemed dedicated to providing top quality patient care. The researcher perceived genuine feelings of desire to provide patients with superb care. This leads the researcher to believe that the focus of current literature, stating that "systems fail the healthcare worker" is not only true, but the key in finding a solution to reduce the occurrence of medical errors.

It was found, through the data collection in this study that the focus of preventive actions focus upon the individual healthcare workers, yet the majority of the problems do not seem to lie here. The researcher feels that the focus needs to be taken off the individual. Administration may want to assess their organizations from the following recommended standpoints in order to find root causes of these perceived system failures:

\section{RECOMMENDATIONS}

Organizational Culture Assessment. In regard to detection, it is suggested that administration contemplate assessing the organizational culture. This may help them begin to understand what may need to change on an organizational level in regard to the occurrence of errors, specifically the reduction of errors. 
Error Reporting System Assessment. An assessment of their current error reporting system may need to be conducted. It is suggested that before providers of healthcare can effectively implement a system that promotes the reduction of errors, they must first gain an understanding of the current system.

Corrective Action Procedures Assessment. Depending upon the above stated assessments, subsequent implications may vary. However, in general, it may be beneficial for healthcare personnel to focus on the aspect of the system that denotes how corrective actions are decided upon. Since the majority of literature states that errors occur due to system breakdowns and not incompetent personnel, efforts should be directed at correcting the systems that may not be effectively working.

Procedural Handbooks and Manuals Assessment. It is recommended that an assessment of handbooks and manuals be assessed. Furthermore, it is recommended that the system of communicating the handbooks and manuals to front-line personnel be assessed in order to analyze possible breakdowns.

\section{AUTHOR INFORMATION}

Monica Law began a full-time career in healthcare in 1993, employed in an acute care hospital as a Radiologic Technologist. She later left to work in an urgent care setting and was promoted to Radiology Department Manager. Monica completed a Master's Degree in 1999 began to work on a Ph.D. In 2004, Monica completed her Ph.D. in Learning and Performance Systems, with an emphasis in Human Resources/Training and Development at The Pennsylvania State University in State College, Pennsylvania. Monica currently is employed as an Assistant Professor at Marywood University and works as an independent consultant focusing on strategic planning for nonprofit organizations. E-mail: Mlaw2@bloomu.edu

\section{REFERENCES}

1. Adams, J., Jaffe, W., \& Rosenbloom, M. (2001). Patient care efficiency and medical error reduction using pda-based medical information. Academic Emergency Medicine, 8(5), 587-599.

2. $\quad$ Argyris, C. \& Schon, D. (1997). Organizational Learning II. Reading, MA: Addison Wesley.

3. $\quad$ Babbie, E. (1998). The practice of social research ( $8^{\text {th }}$ ed.). Belmont, CA: Wadsworth.

4. Cooper, J. B. (2001). Current research on patient safety in the United States. Chicago: National Patient Safety Foundation.

5. $\quad$ Corrigan, J. M., Donaldson, M. S., \& Kohn, L. T. (2000). To err is human: Building a safer health system. Washington DC: National Academy Press.

6. Henneman, E.A., Gawlinski, A., \& Giuliano, K.K. (2012). Surveillance: a strategy for improving patient safety in acute care and critical care units. Critical Care Nurse 32(2). 9-18.

7. Horst, M. A. (2000). Organizational expertise research methodology for investigation of customer service performance and competencies in physician practices (Doctoral dissertation, The Pennsylvania State University, 2000). Dissertation Abstracts International, 61, 4643.

8. Institute for Healthcare Improvement. (2013). http://www.ihi.org/Pages/default.aspx

9. Isaac, S., \& Michael, W. B. (1997). Handbook in research and evaluation. San Diego, CA: Educational and Industrial Testing Services.

10. Jonassen, D. H., Tessmer, M., \& Hannum, W. H. (1999). Task analysis methods for instructional design. Mahwah, NJ: Lawrence Erlbaum Associates.

11. Law, M. (2011). An empirical investigation into the administrative procedures taken in response to detection of medical errors within acute care hospitals in Pennsylvania. American Journal of Health Sciences. 2(1).

12. MacReady, N. (2000). Second stories, sharp ends: Dissecting medical errors. The Lancet, 355(9208), 994. Retrieved May 24, 2001, from http://pdf.thelancet.com/pdfdownload?uid=llan.355.9208.news.1895.1\&x=x.pdf

13. Maxwell, J. A. (1996). Qualitative research design. Thousand Oaks, CA: Sage.

14. Morgan, G. (1989). Creative organization theory. Newbury Park, CA: Sage.

15. Morgan, G. (1997). Images of organizations. Thousand Oaks, CA: Sage.

16. Narayanan, V. K., \& Nath, R. (1993). Organization theory: A strategic approach. Boston: Irwin. 
17. Noe, R. (2002). Employee training and development. McGraw-Hill.

18. O'Leary, D. S. (2000, February). Statement of the Joint Commission on Accreditation of Healthcare Organization. Statement presented at the United States Senate subcommittee on labor, health and human services, and education of the Senate committee on appropriations, Washington DC: Joint Commission of Accreditation of Healthcare Organizations.

19. O'Leary, D. S. (2000). Accreditation's role in reducing medical errors. Joint Commission on Accreditation of Healthcare Organizations. Oakbrook Terrace, IL: Joint Commission on Accreditation of Healthcare Organizations.

20. Pate, B., \& Stajer, R. (2001). The diagnosis and treatment of blame. Journal forHealthcare Quality, 23(1) 4-8.

21. Patton, M. (1997). Understanding research methods: An overview of the essentials. Los Angeles: Pzrczak.

22. Patton, M. (1999). Enhancing the quality and credibility of qualitative analysis. Health Services Research, 34(5), 1-15.

23. Patton, M. (2002). Qualitative research and evaluation methods. Thousand Oaks, CA: Sage.

24. Rossett, A. (1995). Needs Assessment. In Anglin, G. J. (Ed). Instructional technology: Past, present, and future, p.183-196. Englewood, CO: Libraries Unlimited, Inc.

25. Rothwell, W. J. (2002). The workplace learner. New York: AMACOM.

26. Rothwell, W. J. (1996). Beyond training and development. New York: AMACOM.

27. Wong, B.M., Levinson, W., \& Shojania, K.G. (2012). Quality improvement in medical education: current state and future directions. Medical Education. 46(1). 107-119. 
NOTES 